\title{
Managing Human Reliability In The Context Of Telework - An Approach Based On The Job Demands-Resources Model, Combined With The Bow-Tie Method
}

\author{
Jean-Jaques Kohler \\ Geneva School of Economics and Management, University of Geneva, Switzerland. E-mail: jean- \\ jaques.kohler@etu.unige.ch
}

\author{
Emmanuel Fragniere \\ School of Management, HES-SO Valais-Wallis, Sierre, Switzerland and University of Bath, Bath BA2 7AY, United \\ Kingdom. E-mail: emmanuel.fragniere@hevs.ch
}

As stated in the framework provided by the Job Demands-Resources (JD-R) model (Bakker and Demerouti, 2008), the demand dimension corresponds to the constraints imposed by the organization such as work pressure and the resource dimension corresponds to the advantages offered by the organization such as autonomy or social support. These two dimensions of demands and resources thus counterbalance each other and define the level of work commitment and finally its consequences in terms of performance. In the context of telework, which was the rule during the period of containment due to the COVID crisis, our qualitative field survey (involving more than 80 people) revealed numerous human risks such as demotivation, difficulties in resting on clear work instructions or a loss of meaning at middle management level had a direct effect on human reliability (Dhillon, 2013) and generally on work engagement. The problem is that the risk of a decline in work commitment is not something visible to the organization. We therefore propose to combine the JD-R model with the Bow-Tie method (Khakzad et al., 2012). Thus, the event becomes the work engagement, the threats, the demands (here we add the confinement) and the resources and the consequences correspond to the performance. This model is illustrated for the case of student recruitment and shows that a series of preventive controls must be put in place upfront.

Keywords: Bow-Tie method, Demotivation risk, Human reliability, Job demands-resources model, Work engagement.

\section{Introduction}

On the 31st of December 2019, the Wuhan Municipal Health Commission, People's Republic of China, informed the city community about the early signs of a pneumonia outbreak. In response to this information, Hong Kong Government Centre for Health sent a general appeal to the public to maintain hygiene and precautions when travelling outside Hong Kong. Beginning of January 2020, Chinese authorities have determined that the outbreak is caused by a novel coronavirus (named COVID-19 starting February 2020). On 23th of January, the Central Government of China imposed a lockdown in Wuhan and other cities in Hubei in an effort to quarantine the center of the outbreak of coronavirus disease. This lockdown affected a total of about 57 million people. In the meantime, the coronavirus continues to gain ground, not only in the Asia area, but also in Europe. On the 13rd of March 2020, the World Health Organization Director-General said that Europe had become the epicenter of the pandemic with more reported cases and deaths than the rest of the world combined, apart from the People's Republic of China. In light of the continuous spread of the coronavirus more and more cities and countries imposed a quarantine period or lockdown to their population with an access to the critical infrastructures, such as food shops, banks and hospitals. Governments around the world requested public and private companies to work from home as much as possible and on a very short period of time. For some of them, the switching was done in an improvised manner. For a lot of employees and students, a piece of the dining table became a desk for several months. To find an adequate computer or laptop and also a decent communication network to connect to the companies or universities networks were a real challenge due to the rapid increase of demand in a very short period of time. In a recent research Kohler and Fragnière (2020) highlighted the importance to prepare the crisis team for better improvisation that must orchestrates a large number of heterogeneous actors in a very short time. The management and the good resolution of the crisis is not limited solely to the crisis teams but rely also to different actors that could be internal or external to a company, organization or a government. 
In this paper, and because the universities were impacted by the lockdown imposed by some governments, we are taken an interest in how university's student reacted in a context of telework. Our analysis, through semi-directive interviews, highlighted an increase of human risks. In order to better identify this type of risks, we propose to combine the Job DemandsResources (JD-R) model (Bakker and Demerouti, 2008) with the Bow-Tie method (Khakzad et al., 2012). The JD-R model studies the functioning of employees' well-being by comparing two main elements: job requirements and job resources. The imbalance of these elements could be a source of stress for the employees. The Bow-Tie method is a root cause analysis tool used to analyze and demonstrate causal relationships in risk scenarios. It gives a visual summary of multiples threats and consequences around an event.

The model we have developed, which is an approach to managing human reliability in the context of teleworking, combines the Job Demand-Resource model and the Bow-Tie method. To our knowledge this is the first time that JD-R and Bow-Tie are brought together to address cause and effect relationships in a context of dematerialization of administrative work processes. In this theoretical research, we only focused on the human risks and not the opportunity dimension of telework. It is clear that the subject of telework requires in-depth field investigations in order to be properly understood. In parallel to this work we have been conducting for some years ethnographic surveys on the digitalization of work in general (e.g. Dubosson et al., 2019). In particular, we are at the end of a relative one on telework in the COVID period. In the present paper, we have just used the transcripts of the semi-directive interviews of the latter survey to make a theoretical development on human reliability in the telework context. On the basis of our model, it is thus possible to establish "intangible" cause and effect relationships through JD-R and to "tangibilize" them through bow tie. There is already a great deal of confusion around the subject of telework during the COVID period. It will take several years to digest all the scientific studies carried out on the subject [Abukari and Bankas (2020); Belzunegui-Eraso and Erro-Garcés (2020); Raišienè et al. (2020)].

This paper is organized as follows. In Section 2 , we present a brief literature review related to critical infrastructure and its inherent link with human reliability. In Section 3, we show how we have developed a new theoretical model combining the Bow-Tie approach with the wellknown occupational stress JD-R involving the Work Engagement dimension. In Section 4, we provide the first insights we have observed from a qualitative survey we have conducted among 80 Swiss professionals to learn about the human risks that were specifically related to the imposed telework phase due to the COVID crisis. In Section, 5 we illustrate the new model we have developed with a case study related the hiring of new talents just before the COVID crisis. In Section 6, we conclude and provide directions for further research.

\section{Literature Review}

When a significant risk occurs, it is usually referred to as a disaster or a crisis. Fritz and Williams describe disasters and catastrophes as events for which a society is in serious danger and suffers such impacts and losses that the social structure is disrupted and the performance of all or some of the essential functions of the society is prevented. Fragnière and Sullivan (2007) define the crisis as an event that puts strong, destabilizing pressure on organizations facing critical situations and subject to strong external and internal pressures. Thus, the same event may be considered as a disaster or a crisis. The concept of critical infrastructures as described by Hull and al. (2006) includes all the assets that are so vital for a country that its destruction or degradation could have a negative impact on the essential functions of a government, the national security, the national economy or the public health. In case a part of a critical infrastructures becomes inactive following a terrorist attack, a human error or a natural disaster could have negative impacts on other infrastructures as explained by Löschel et al. (2010).

Human risks are embedded in the operational risks. The Base Committee (Bank of International Settlements, 2001) defines operational risk as "the risk of direct and indirect loss resulting from inadequate or failed internal processes, people and systems or from external events.". Boshoff (1997) highlights the fact that companies are subjected to human risks because errors are an "unavoidable feature of all human endeavors".

Dubosson et al. (2017) built a new theory using the "job demands and resources" (JD-R model) where their results suggest that human risks lead to ill-being and value destruction.

Teleworking could have positive and negative effects on each individual. It seems that for some people telework is comparable to a stressful environment. The consequences of telework can vary from person to person. As explained by Behrman and Perreault (1984), stress can improve the performance of the individual. In contrast, Toderi et al (2015) show the negative effects of stress on individuals by reducing their work performance and causing health problems.

In a survey of Lithuania's Employees during the COVID-19 quarantine period, Raišienè et al. 
(2020) show the differences in the assessment of the advantages and disadvantages of telework as well as of the individual characteristics from a remote worker.

During the COVID-19 an increasing number of firms have been adopting teleworking as a measure to continue the business activity and to ensure employees' health (Belzunegui-Eraso and Erro-Garcés, 2020).

\section{On developing a preventive human reliability safety model}

When damage occurs, it most often results from multiple causes. But catastrophe can often be prevented by dealing adequately with several minor risks. This requires adopting a dynamic view toward risk analysis. The text ERM (Enterprise Risk Management), which was adopted by COSO (The Committee of Sponsoring Organization of the Treadway Commission, www.coso.org) in 2005, has (compared to the first version) introduced the notion of "identification of events". This acknowledges that cause-andeffect is "fundamental to the analysis of risk. In identifying risks, dynamic linkages between the various risks can be charted using tools such as cause-and-effect diagrams, flow charts, influence diagrams, and decision trees.

The flow chart presented in Figure 1 emphasizes the importance of control in preventing risk contagion-the manifestation of one risk triggering a cascade of others, ultimately resulting in serious damage. The first signal is a threat that a risk is materializing. If the ICS (Internal Control System) lacks proper preventive measures (e.g., inadequate due diligence in the credit department), an undesirable event might result (e.g., granting loans to felons, conmen, and embezzlers and seeing the rate of bad loans soar). This can be applied even at the individual level.

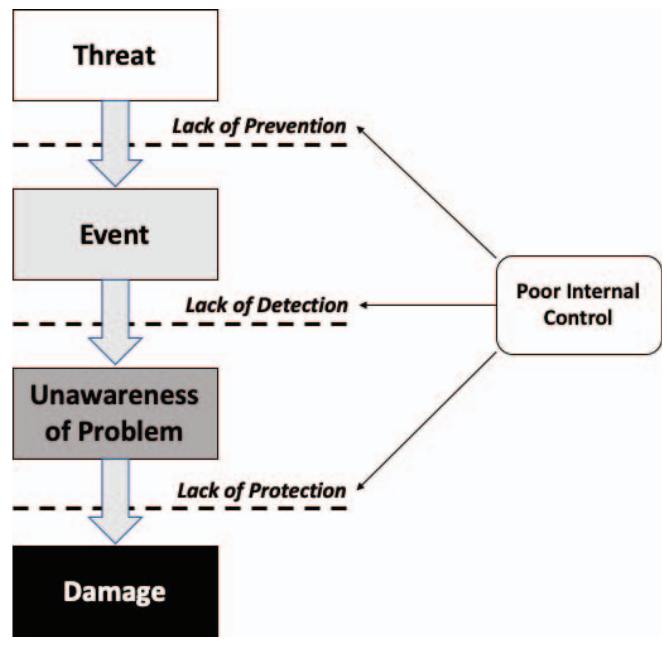

Fig. 1. Showing how a major event might follow a sequence where prevention does not stop the realization of an event, where then it is not possible to detect it and finally where protection or recovery measures won't prevent the final damage from happening. This is typically the illustration of a poor ICS.

Continuing down the flow chart, a lack of detection system, or a defective system, might generate other inefficiencies within the company. For example, a lack of accurate management information systems to reconcile assets could result in a higher shrinkage rate, higher risk of audit, and excessive resources spent to meet reporting requirements. Ultimately, if nobody takes note of the problem and thus no one implements protective measures-such as regular reviews of business practices and areas that can be optimized-the cascading damage might result in a major breakdown of the business, thus preventing management from reaching its objectives.

There is a great, natural draw toward doing things "the way they have always been done" simply because it works. Just because something works, though, does not mean it is working well. Some things that are not working well may end up not working at all if they are not improved.

Unfortunately, it is common for people to get mired in a process that has been in place for some time, even if it is outdated. To sidestep this, management must establish a regular review of all processes, similar to getting a regular checkup at the doctor's office, just to make sure everything is up to date, in good working order, and optimized. This is a major advantage of the anticipatory approach toward safety as shown in Figure 2. 


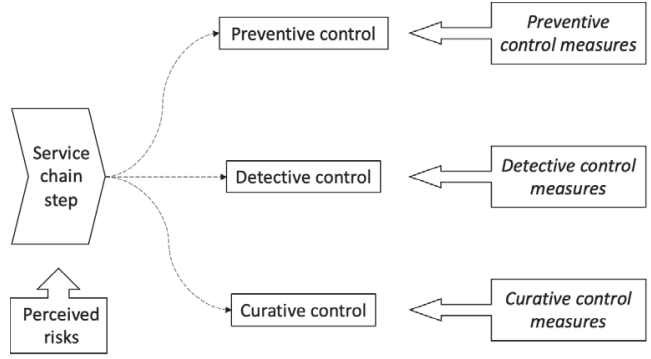

Fig. 2. A model for perceived risks adapted to the service sector involving preventive, detective as well as protective controls (Dubosson et al. 2006).

To monitor these stages, cause-and-effect analyses (e.g., fishbone diagrams) are sufficient for managers to properly rank risks and monitor the controls for each risk stage. Threats (upstream risk) should be handled with the same care as damages (downstream risk). Allocation of risk resources should be changed to be more oriented toward the identification of threats and the implementation of detective controls to prevent any contagion of risks.

Consequently, our control design involves three types of tests:

- Whether the threat is associated with a prevention system

- Whether the event is associated with a detection system

- Whether the ignorance of the problem is associated with a protection (or curative) system

Compared with a traditional approach, this will foster an ex ante ("beforehand") treatment of risk as opposed to an ex post ("after the fact") treatment. It is well known that acting in an ex ante manner will cost less and will be more efficient. Prevention is often cheaper than the cure.

The Bow-Tie as a visual tool (see Figure 3 ) is interesting and practical, especially for setting up controls, as we have seen above, to establish preventive, detective and curative controls. In a case of "physical" risk, the event is often visible, such as an explosion or fire. However, when the event that occurs corresponds to a human-type risk, there are often no indicators to detect it. For example, during the period of COVID, many companies had to switch to teleworking mode overnight. Productivity was an issue for these companies. If we refer to the scientific literature, one of the dimensions that has been much studied is work engagement (Bakker et al. 2008, see
Figure 4 for the JD-R model involving the dimension Work Engagement). This dimension is often specified by the following indicators: vigor, dedication and absorption (Lu et al., 2016).

As soon as employees are at home with their children, not necessarily in a room equipped for work, it is very likely that vigor, absorption and dedication can be affected by a whole series of elements that are no longer directly controllable by the company. Wrongly (Cross et al., 2016), one can think that work engagement is affected by laziness. As in any BCP, it is taken into account that the teams managing the crisis and the return to normal must be replaced regularly.

To our knowledge, this is the first theoretical model of human reliability to evaluate cause and effect relationships in a telework logic and therefore the digital transformation of the company. Whereas traditional work processes are partly visible (linked to operating modes), telework is based on dematerialized and largely invisible or intangible processes. As a result, it becomes extremely difficult to detect human risks or vulnerability such as occupational stress. Based on the JD-R theoretical model, this is what we can do, in particular by identifying aspects of job demands and job resources through a qualitative field survey. Then thanks to the Bow-Tie visualization model we are able for the first time to show cause and effect relationships from the origin to the event (e.g. a decrease in productivity which is not necessarily visible) and then to the consequences (e.g. a decrease in creativity).

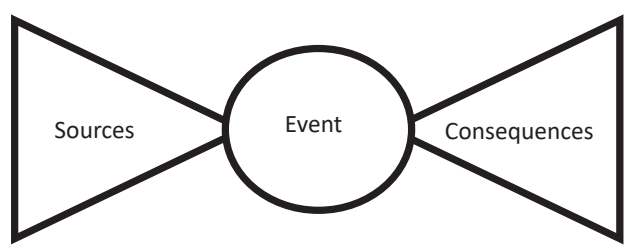

Fig. 3. A simple visual representation of the Bow-Tie model that enables the safety manager to identify sources as well as consequences related to a major event to facilitate the setup of preventive and protective controls. 


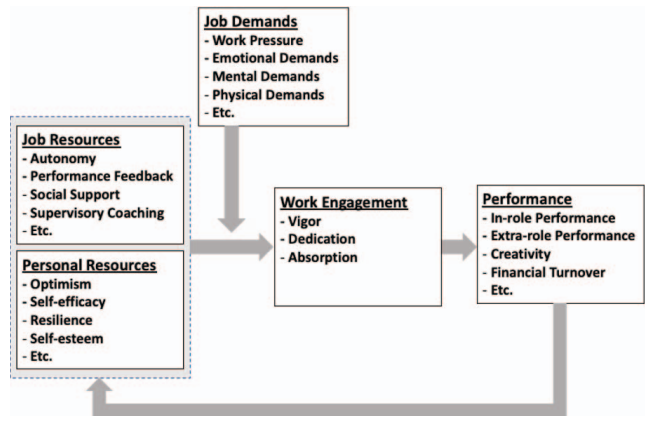

Fig. 4. This figure corresponds to Job Demands Resources model that includes as an output the work engagement (Bakker and Demerouti, 2008).

In Figure 5, we show how we mixed the Bow-Tie logic with the Job Resources Demand model involving the Work Engagement dimension.

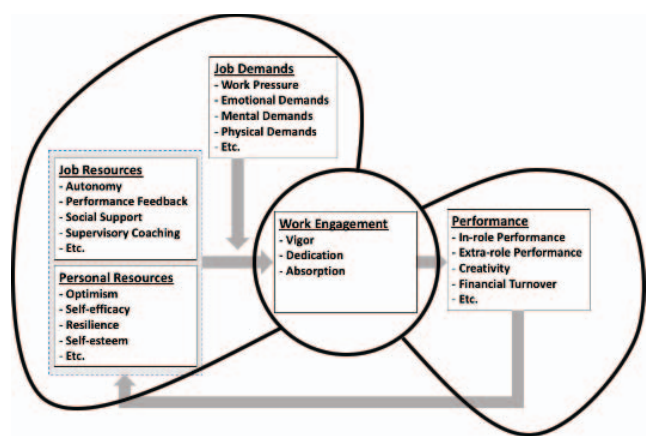

Fig. 5. A simple drawing over the job demands resources model to show how the Bow-Tie method can be used to deal with human reliability in the general case of occupational stress.

\section{First insights of an exploratory study related to human risks in the context of imposed telework}

In this paper, the most appropriate method for exploring this new topic of forced telework due to the COVID crisis seemed to be based on interpretivism (Saunders et al., 2019). Through it, we tried to understand how professionals reacted in a telework context during the lockdown. In order to collect data that will allow us to better understand the factors that could have a negative impact on these persons, we used the ethnographic approach as described by Saunders et al. (2019). We were able to interview 80 different socio-economic profiles of people. For example, some of them are single and live alone in a quiet room, others live in an apartment with children. Their previous experiences did not put them on an equal footing with regard to telework.

We created a questionnaire with the objective of identifying elements that could generate human risks. The questionnaire was designed to allow the respondents to express themselves freely about their experiences of telework and to obtain elements related to human risks. We collected data through semi-structured interviews lasting an average of one hour. All interviews were transcribed, and the data compiled for analysis.

The initial results are presented in this document. We still need to go further with a more in-depth content analysis. Detailed results of this study will appear in a subsequent study.

People have told us that one of the main human risks is demotivation. The main factor is the reduction of social interactions with the other colleague or with other people in general.

Our interviews revealed that some people suffer from computer problems related to hardware or communication network. It seems that some of them were not equipped to telework adequately, which creates stress and can lead indeed to de-motivation.

Staying alone, without direct supervision, was seen as an element that could increase human risks due to poor communication between the different actors or the problem of coordination in projects. Some interviewees stated that they should be encouraged to deliver a good level of productivity in a timely manner to help them be more involved.

\section{Case study: risk of missing the integration of a talent hired in a period of confinement.}

\subsection{Organizational Talent Context}

A simple case study is proposed here to illustrate the model proposed in this paper. Talent management is crucial in any organization today to drive innovation (Marin-Garcia et al., 2011). Numerous scientific studies also show the risks that newly hired talent does not fully integrate within their starting period (Zhang et al., 2015). This can create enormous damage for the company in terms of its innovation business objectives and also for the talent that may have difficulty bouncing back after this bad experience.

\subsection{Specific case of containment}

This talent integration risk is therefore omnipresent in organizations, except that during the COVID crisis and the need to switch to teleworking made it even more difficult to integrate them. Our exploratory fieldwork has also shown that, in the case of talent, there is a significant additional suffering, especially as it is 
often impossible (in a situation of lockdown) to "demonstrate" one's talents in the workplace.

\subsection{JD-R model (Job Demands-Resources)}

In the case of the JD-R in its version integrating the construct work engagement, we link the case of the incident of the talent that fails to integrate directly to the unsuccessfulness of the work engagement and more precisely by referring to the associated indicators vigor, absorption and dedication to the impossibility that these last three are fully manifested.

Indeed, talent can be considered as a racing beast, and we therefore find ourselves in a situation where either work engagement is total or not at all. In Figure 6, we present Bow-Tie event, which corresponds to a non-work engagement, that is hardly noticeable in telework mode. This is due to the fact that the remote worker, often at home, is no longer part of a team and it is therefore difficult if there is a significant drop in his commitment to detect it. However, we will first fill in the Bow-Tie on the right hand side, at the level of consequences. The consequences will probably be visible much later than one might imagine, because even the annual financial reports will not be able to identify these problems. Indeed, the contribution of talent remains very intangible in the short and medium term. In the longer term, we will see that the company is no longer as innovative as we might have imagined, but even more seriously, it is likely not to be very attractive to other talents in the future. We can see in this Bow-Tie the seriousness of these consequences in the achievement of the company's essentially strategic objectives, which are not very measurable as well as very difficult to trace.

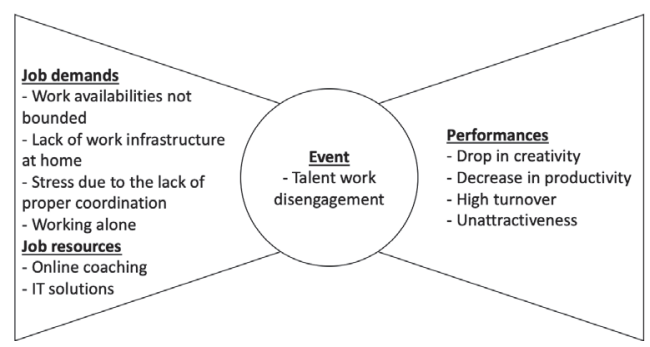

Fig. 6. A Bow-Tie instance based on the job demands resources model to assess the case of a major event of work disengagement of talents that have been hired before the lockdown period.

On the left side of the Bow-Tie, the choice of threat (or source) elements can be based on the theoretical model of the JD-R model and on the numerous empirical studies that have been carried out.
In particular for personal resources have little or no basis in a typical profile (or a few typical talent profiles). It is in the JD-R equation what talent very often brings with great energy, curiosity, fighting spirit and a propensity to work in a team. Where the downside is, it's in our situation of confinement, earlier in the round of Job Demands and Job Resources constructs. Indeed, on the one hand Job Resources will be reduced (especially the company atmosphere, direct mentoring from senior staff, company infrastructures with often in technology companies a university "campus" logic favoring freedom, interdisciplinarity and interaction). On the other hand, the Job Demands or the constraints linked to the company will increase, notably by the fact that only the confinement indicator will constitute an important additional weight compared to the other demands which remain valid.

\subsection{Human reliability recommendation}

This case study is very generic of course and in reality each situation is different. So, the data filling in the Bow-Tie combined with the JD-R will be very specific. However, this case study based on our theoretical approach shows one thing for sure. The commitment of talent in a period of confinement, semi-confinement or even future periods without, hopefully, the risk of COVID, will remain very vulnerable, because it is very likely that teleworking will remain anchored in the daily life of companies which will constitute what is called an emerging risk (Dollar et al., 2007) for companies.

Thus, we see in the proposed generic case, that the curative controls that could be put in place at the level of consequences are extremely costly and most certainly come too late to restore the situation. Similarly, the detection of the major incident of a situation of non-work engagement of newly recruited talent is extremely difficult. On the other hand, on the left side of the Bow-Tie, all the possible controls to deal with the threats (or sources) related to Job Demands and Job Resources are numerous and widely described in the literature and are often behavioral in nature.

\section{Conclusion}

In this paper, we deal with the theme of human reliability in a context of sudden telework due to the COVID crisis. We posit that in this situation major incidents are essentially linked to human failures and weaknesses that are extremely difficult to detect. This leaves the company unaware of these major incidents which will have a significant long-term impact on its overall performance. It will therefore be very difficult to get the company back on its feet. In an exploratory 
field survey that we conducted among 80 people in Switzerland who suddenly had to work online during the containment period, we were able to identify the most important risks encountered in dealing with this unprecedented crisis situation. In particular, fatigue, concentration difficulties, demotivation, loneliness, lack of clarity in work instructions were revealed and yet many of these people put a lot of energy into their daily lives to compensate for these difficulties related to teleworking. Nevertheless, they still feel that such a situation in the long term (which seems to be on the horizon) is not sustainable. And yet the company does not seem to recognize this. Yet, in crisis management when deployed in $\mathrm{BCP}$, it is well known that shifts between teams are necessary in order to alternate between managing the crisis for a return to normal in degraded mode and resting to regain strength. On the basis of this observation, we came up with the idea of developing a new human reliability model in the context of teleworking in order to prevent human failures which are more than predictable and unavoidable. We have combined the well-known approach of the Bow-Tie method with a very well-known model of professional stress, the Job Demands-Resources in its version (2008) leading to work engagement. As these elements of work engagement are very little detectable and the JD$\mathrm{R}$ model helps us to identify their sources, it allows us to manage elements of human reliability that are not visible and unavoidable by integrating as a precautionary principle a whole series of lowcost preventive controls to reduce the risk of a sudden drop in work engagement in teleworking mode. This model is illustrated for the case of student recruitment and shows that a series of preventive controls must be put in place upfront.

\section{References}

Abukari, A. M. and E.K. Bankas (2020). Some cyber security hygienic protocols for teleworkers in COVID-19 pandemic period and beyond. International Journal of Scientific \& Engineering Research, 11(4), 1401-1407.

Bakker A. B. and E. Demerouti (2008). Towards a model of work engagement, Career Development International 13, 209-223.

Bakker, A. B., Schaufeli, W. B., Leiter, M. P., \& Taris, T. W. (2008). Work engagement: An emerging concept in occupational health psychology. Work \& stress, 22(3), 187-200.

Behrman, D. N. and W. D. Perreault Jr. (1984). "A Role Stress Model of the Performance and Satisfaction of Industrial Salespersons." Journal of Marketing 48 (4), 9-21.

Belzunegui-Eraso A. and A. Erro-Garcés (2020). Teleworking in the Context of the Covid-19 Crisis. Sustainability 2020, 12(9), 3662.
Boshoff, C. (1997). An experimental study of service recovery options. International Journal of Service Industry Management 8(2), pp. 110-130.

Cross, R., R. Rebele, and A. Grant (2016). Collaborative overload. Harvard Business Review, 94(1), 16

Dhillon, B. S. (2013). Human reliability: with human factors. Elsevier.

Dollard, M., N. Skinner, M. R. Tuckey, and T. Bailey (2007). National surveillance of psychosocial risk factors in the workplace: An international overview. Work \& Stress, 21(1), 1-29.

Dubosson, M., E. Fragnière, and B. Milliet (2006). A control system designed to address the intangible nature of service risks. In 2006 IEEE International Conference on Service Operations and Logistics, and Informatics, 90-95

Dubosson, M., E. Fragnière, M. Pasquier, and C. Reynard (2017). Exploring occupational stress in the Swiss wealth management sector, How could human risk lead to value destruction. European Review of Service Economics and Management, 1 (3), 17-45

Dubosson, M., E. Fragnière, and D. Rochat (2019). Perceived risks regarding the impact of digitalization on the future of work. European Review of Service Economics and Management, 1(7), 17-43

Dubosson, M., E. Fragnière, D. Rochat, M. Sitten and E. Berdeaux, (2020). Confusion between Artificial Intelligence and digitisation at work-Ignorance or blind trust? European Review of Service Economics and Management, 97-118.

Hull, R. N., D. A. Belluck and C. Lipchin (2006). A framework for multi-criteria decision making with special reference to critical infrastructure: policy and risk management working group summary and recommendations. In Ecotoxicology, Ecological Risk Assessment and Multiple Stressors, 355-369

Kohler, J-J. and E. Fragnière (2020). Crisis team setup for better improvisation. In Proceedings of the 30th European Safety and Reliability Conference and the 15th Probabilistic Safety Assessment and Management Conference

Khakzad, N., F. Khan, and P. Amyotte (2012). Dynamic risk analysis using bow-tie approach. Reliability Engineering \& System Safety 104, 36-44.

Löschel, A., U. Moslener and D. T. G. Rübbelke (2010). Energy Security-Concepts and Indicators. Energy Policy 38 (4), 1607-8.

Lu, L., A. C. C. Lu, D. Gursoy and N. R. Neale (2016). Work Engagement, Job Satisfaction, and Turnover Intentions: A Comparison between Supervisors and Line-Level Employees. International Journal of Contemporary Hospitality Management 28 (4), 737-761.

Marin-Garcia, J. A., L. E. Aznar-Mas, and F. GonzálezLadrón-de-Guevara. (2011). Innovation types and talent management for innovation. WPOMWorking Papers on Operations Management, 2(2), 25-31. 
Raišienè, A. G., V. Rapuano, K. Varkulevičiūte, and K. Stachová (2020). Working from Home - Who is Happy? A Survey of Lithuania's Employees during the Covid-19 Quarantine Period. Sustainability 2020, 12(13), 5332

Saunders, M. N. K., P. Lewis, and A. Thornhill (2019). Research Methods for Business Students (8th ed.). New York: Pearson.

Toderi, S., A. Gaggia, C. Balducci, and G. Sarchielli (2015). Reducing Psychosocial Risks through Supervisors' Development: A Contribution for a Brief Version of the 'Stress Management Competency Indicator Tool'. Science of The Total Environment 518-519 (June), 345-51.

Zhang, J., M. F. Ahammad, S. Tarba, C. L. Cooper, K. W. Glaister, and J. Wang (2015). The effect of leadership style on talent retention during merger and acquisition integration: Evidence from China. The International Journal of Human Resource Management, 26(7), 1021-1050. 